\title{
An observationally based estimate of the climate sensitivity
}

J. M. Gregory ${ }^{1}$, R. J. Stouffer ${ }^{2}$, S. C. B. Raper ${ }^{3}$, P. A. Stott ${ }^{1}$, N. A. Rayner ${ }^{1}$

(1) Met Office Hadley Centre, Bracknell, UK

(2) Geophysical Fluid Dynamics Laboratory, Princeton, USA

(3) Climatic Research Unit, University of East Anglia, Norwich, UK; and Alfred Wegener Institute for Polar and Marine Research,

Bremerhaven, Germany

5th July 2002 


\begin{abstract}
A probability distribution for values of the effective climate sensitivity, with a lower bound of $1.6 \mathrm{~K}$ (5percentile), is obtained on the basis of the increase in ocean heat content in recent decades from analyses of observed interior ocean temperature changes, surface temperature changes measured since 1860, and estimates of anthopogenic and natural radiative forcing of the climate system. Radiative forcing is the greatest source of uncertainty in the calculation; the result also depends somewhat on the rate of ocean heat uptake in the late 19th century, for which an assumption is needed as there is no observational estimate. Because the method does not use the climate sensitivity simulated by a general circulation model, it provides an independent observationally based constraint on this important parameter of the climate system.
\end{abstract}

\title{
1 Introduction
}

The equilibrium climate sensitivity is the conventional measure of the equilibrium climate response to radiative forcing resulting from greenhouse gases and other anthropogenic and natural causes. It is defined as the steady-state change in global average surface temperature due to a doubling of the carbon dioxide concentration, and is estimated to lie between 1.5 and $4.5 \mathrm{~K}$ (Cubasch et al., 2001), largely on the basis of experiments with general circulation models (GCMs). This wide range was informally obtained from the model results, and does not correspond to any particular probability limits. Despite considerable improvements in many aspects of the simulation of 20th century climate by GCMs, the range has remained essentially unchanged during the last two decades, and is the greatest source of uncertainty in climate change projections for the 21 st century.

GCMs indicate that the increase in global-average outgoing radiative flux when the climate is perturbed from a steady state is proportional to the global-average surface temperature change $\Delta T$. During time-dependent climate change, the imbalance between the imposed radiative forcing $Q$ and the radiative response $\lambda \Delta T, \lambda$ being a constant, is absorbed by the heat capacity of the system, which resides overwhelmingly in the ocean (Levitus et al., 2001). Hence

$$
F(t)=Q(t)-\lambda \Delta T(t)
$$


where $t$ is time and $F$ is the heat flux into the ocean. Equation 1 has often been employed as the basis for energy-balance climate models.

In the unperturbed steady-state climate, $Q=F=0$ and $\Delta T=0$. If $Q$ is raised from zero to some positive value, $F$ becomes positive, additional heat is stored in the ocean, and $\Delta T$ rises. If $Q$ then remains constant, $F$ returns to zero over time, as the climate approaches a new steady state in which $\Delta T=Q / \lambda$. From its definition, the equilibrium climate sensitivity $\Delta T_{2 \times}=Q_{2 \times} / \lambda$, where $Q_{2 \times}$ is the forcing that results from a doubling of the $\mathrm{CO}_{2}$ concentration.

Although it is defined in terms of a steady-state climate, the climate sensitivity can be estimated from any climate state. Provided we know $F, Q$ and $\Delta T$, we can calculate $\lambda$ from Equation 1 and hence $\Delta T_{2 \times}$ (e.g. Cubasch et al., 2001). Some results with coupled atmosphere-ocean GCMs (AOGCMs) suggest that $\Delta T_{2 \times}$ (called the "effective" climate sensitivity when calculated from an unsteady climate) might not be constant even on the century timescale (Senior and Mitchell, 2000), although AOGCM experiments do not give rise to any expectation that it will change rapidly. If $\Delta T_{2 \times}$ is not constant, its usefulness for predicting future climate change is of course limited, and an estimate based on recent climate change is the most appropriate one to use. The utility of the climate sensitivity also depends on the response being independent of the nature of the agent causing the radiative forcing.

\section{Method}

Recent studies aimed at setting constraints on the climate sensitivity have used climate models in which $\lambda$ can be varied and heat uptake by the ocean is modelled simply (Wigley et al., 1997; Andronova and Schlesinger, 2001; Forest et al., 2002). The approach is systematically to adjust the parameters and inputs of the model, comparing the simulated results with observed surface temperature changes. The results give a range for $\Delta T_{2 \times}$ which is even wider than $1.5-4.5^{\circ} \mathrm{C}$.

Using a model of ocean heat uptake inevitably involves assumptions about its mechanisms. Estimates of ocean heat uptake can instead be made using the five-year running means of observed ocean interior temperature changes of Levitus et al. (2000). The increase in heat content from 1957 to 1994 , the period of best data coverage, is $(19.0 \pm 9.0) \times 10^{22} \mathrm{~J}$. The stated uncertainty, of two standard devi- 
ations, relates to measurement and sampling uncertainties. Denoting the time-average for 1957-1994 by an overbar, Equation 1 becomes

$$
\lambda \overline{\Delta T}=\bar{Q}-\bar{F} .
$$

The heat content increase yields $\bar{F}=0.32 \pm 0.15 \mathrm{~W} \mathrm{~m}^{-2}$ (expressed per unit area of the entire world, not just the ocean surface).

$\Delta T$ is defined with respect to the steady-state climate for zero forcing. Sufficient measurements exist to estimate global average temperature changes back to 1860 , but the climate of that period was not a steady state, not least because anthropogenic greenhouse gases began to increase in the latter part of the 18th century. In fact, there has probably never been a steady-state climate, because solar output fluctuations and volcanism produce continual variations in radiative forcing on a shorter timescale than that required for the climate system to reach equilibrium.

As we do not know the global average temperature for the steady state, we instead consider differences between the recent and an earlier period, as widely separated as possible in order to maximise the climate change signal. We take the difference between Equation 2 for 1957-1994 and a corresponding equation for the period 1861-1900, denoting the differences between the means for the two periods as $\overline{\Delta T}^{\prime}, \bar{Q}^{\prime}$ and $\bar{F}^{\prime}$. Hence

$$
\lambda \overline{\Delta T}^{\prime}=\bar{Q}^{\prime}-\bar{F}^{\prime}
$$

Folland et al. (2001) calculated annual surface temperature anomalies, with uncertainties, by combining land- and ocean-based observations using an optimal averaging technique. From their data, the difference in global average temperature between the two periods is $\overline{\Delta T^{\prime}}=0.335 \pm 0.033^{\circ} \mathrm{C}$, where the uncertainty (two standard deviations) was obtained assuming the two periods to be independent, and making allowance for serial correlation of annual values within each period.

No observations exist of past changes in radiative forcing, so this quantity must be estimated. We take into account the effects of greenhouse gases (carbon dioxide, methane, nitrous oxide, halocarbons and tropospheric ozone), anthropogenic sulphate aerosols, solar variation, and volcanic aerosols (Table 1). Greenhouse gas and sulphate aerosol forcing are dominant and of opposite signs. The former is calculated using historical concentrations of the gases and formulae for radiative forcing; there is 
estimated to be a range of uncertainty of $\pm 10 \%$ on the results (Ramaswamy et al., 2001).

The effect of sulphate aerosol is much less precisely known. The patterns of temperature change are sensitive to aerosol forcing. We derive limits for the forcing (Table 1) by comparison of the spatiotemporal patterns of temperature change in observations and experiments with the HadCM3 AOGCM (Stott et al., 2000). The method (see Allen et al., In press) assumes that the patterns simulated by the AOGCM are realistic, but does not depend on the model's forcing or climate sensitivity.

Solar output is thought to have increased in the early 20th century, giving a positive contribution to $\bar{Q}^{\prime}$, for which we take the range of Ramaswamy et al. (2001). Relative to the long-term average, there was a large amount of volcanism during recent decades, including the eruptions of Agung, El Chichon and Pinatubo. Despite the eruption of Krakatoa, the late 19th century was on average less active, resulting in a negative contribution of volcanic forcing to $\bar{Q}^{\prime}$ of $-0.2 \mathrm{~W} \mathrm{~m}^{-2}$ (Andronova et al., 1999), or $-0.4 \mathrm{~W} \mathrm{~m}^{-2}$ (Crowley, 2000).

We obtain a $\pm 2 \sigma$ interval for forcing change $\bar{Q}^{\prime}$ of between -0.3 and $+1.0 \mathrm{~W} \mathrm{~m}^{-2}$, by combining the ranges of the various terms (Table 1), assuming the individual ranges to be normal $\pm 2 \sigma$ intervals. We make this assumption on pragmatic grounds, as we lack knowledge of the probability density function of any of the terms, although we note that a tendency towards normality as one adds more terms is consistent with the central limit theorem.

To complete the calculation, information is needed about the average heat flux into the ocean during 1861-1900, in order to calculate $\bar{F}^{\prime}$. In the absence of observational data, experiments both with AOGCMs and with simpler climate models (e.g. Stott et al., 2000; Forest et al., 2002) commonly assume that the climate was in a steady state at the starting point of their integrations, typically in the late 19th century. We investigate this assumption using the simple climate model of Raper et al. (1996) (which implements equation 1 and calculates $F$ with a one-dimensional upwelling-diffusion ocean model), as tuned by Cubasch et al. (2001) to reproduce results from a range of AOGCMs. In simulations with anthropogenic forcing alone, starting at the onset of substantial industrial emissions of greenhouse gases in the late 18th century, $\bar{F}(1861-1900)$ lies in the range $0.06-0.10 \mathrm{~W} \mathrm{~m}^{-2}$. In simulations with natural forcings alone (volcanoes and solar variation) (Crowley, 2000), starting in the 
year $1000, \bar{F}(1861-1900)$ is coincidentally also $0.06-0.10 \mathrm{~W} \mathrm{~m}^{-2}$. It is positive because the climate is recovering from substantial negative forcing in preceding decades. Making the usual assumption that forcings can be combined linearly, these results suggest an estimate for $\bar{F}(1861-1900)$ of $0.12-$ $0.20 \mathrm{~W} \mathrm{~m}^{-2}$, whereas a steady state would have $\bar{F}(1861-1900)=0$. Treating this range as a normal $\pm 2 \sigma$ interval and calculating the difference from $\bar{F}(1957-1994)$ obtained above, we obtain a $\pm 2 \sigma$ interval for $\bar{F}^{\prime}$ of $0.00-0.32 \mathrm{~W} \mathrm{~m}^{-2}$.

\section{Results}

We calculate $\lambda$ from Equation 3 as a function of $\overline{\Delta T^{\prime}}, \bar{F}^{\prime}$ and $\bar{Q}^{\prime}$, and convert it to $\Delta T_{2 \times}$ using $Q_{2 \times}=$ $3.71 \mathrm{~W} \mathrm{~m}^{-2}$ (Myhre et al., 1998) (Figure 1). We compute the probability distribution of resulting values (Figure 2), assuming $\overline{\Delta T^{\prime}}, \bar{F}^{\prime}$ and $\bar{Q}^{\prime}$ to be independently and normally distributed with the standard deviations derived above, and ignoring the uncertainty of $\sim 1 \%$ in $Q_{2 \times}$ (Myhre et al., 1998), which is negligible by comparison. The effect of internal (unforced) variability of the climate system on $\bar{F}^{\prime}$ and $\bar{Q}^{\prime}$ is also neglected, because estimates based on 1300 years of the HadCM3 control run show these fluctuations to be an order of magnitude smaller than the uncertainties. From the probability distribution of $\Delta T_{2 \times}$ we obtain a $90 \%$ confidence interval, whose lower bound (the 5-percentile) is 1.6 K. The median is $6.1 \mathrm{~K}$, above the canonical range of $1.5-4.5 \mathrm{~K}$; the mode is $2.1 \mathrm{~K}$.

A positive $\bar{F}(1861-1900)$ implies that some of the 20th century warming is a committed response to previous forcing (Weaver et al., 2000). If the late 19th century is assumed to be a steady-state climate, such that $\bar{F}(1861-1900)=0$, the 5-percentile of $\Delta T_{2 \times}$ increases to $2.0 \mathrm{~K}$. On the other hand, if the climate system were assumed always to be in steady state i.e. $\bar{F}^{\prime}=0$, the 5-percentile of $\Delta T_{2 \times}$ would be $1.3 \mathrm{~K}$. Use of a low-diffusivity ocean model might underestimate heat uptake, thus giving smaller $\Delta T_{2 \times}$

The $90 \%$ confidence interval for $\Delta T_{2 \times}$ extends up to infinity, and beyond to negative values (cf. Figure 1). $\Delta T_{2 \times}<0$ if $\bar{Q}^{\prime}<\bar{F}^{\prime}$, which means that heat flux into the ocean has increased by more than the radiative forcing. Negative $\Delta T_{2 \times}$ is unphysical, because it implies the unforced climate system would be unstable to any perturbation generated by internal variability. We infer that $\bar{Q}^{\prime}<\bar{F}^{\prime}$ should be 
regarded as implausible. With $\bar{Q}^{\prime}$ only slightly greater than $\bar{F}^{\prime}, \Delta T_{2 \times}$ is extremely large. Such values can be excluded by paleoclimatic studies, which show that the climate sensitivity of the real world is of roughly the size indicated by GCMs (e.g. Hoffert and Covey, 1992), but do not constrain it more tightly.

The dominant uncertainty in the calculation of climate sensitivity is clearly that pertaining to the estimates of radiative forcing, especially the aerosol forcing (cf. Forest et al., 2002; Knutti et al., 2002; Allen et al., In press). While representing the state of current knowledge, the radiative forcing estimates we have employed are imprecise and undoubtedly incomplete in some respects. Some known negative radiative forcings have been omitted (stratospheric ozone depletion, aerosol from biomass burning, albedo change from land use change) (Ramaswamy et al., 2001), whose inclusion would tend to raise the lower bound of $\Delta T_{2 \times}$. Mineral dust and black carbon aerosol, also omitted, could give positive forcing (Ramaswamy et al., 2001). If we make an informal allowance for the possibility of substantial additional positive forcing by raising the upper bound of the sulphate aerosol forcing to zero, following Andronova and Schlesinger (2001), the 5-percentile of the climate sensitivity falls to $1.1 \mathrm{~K}$. Although the HadCM3 simulations from which the sulphate aerosol forcing was derived did not include nonsulphate anthropogenic aerosols, these may have a somewhat similar geographical distribution to that of sulphate aerosols. To the extent that this is so, the sulphate aerosol forcing resulting from the method includes them as well; otherwise, their omission will be reflected in a greater forcing uncertainty.

We consider that the lower bound is an important constraint on climate sensitivity, because it is objectively derived, and independent of GCM results for $\Delta T_{2 \times}$. Although the lower bound does not lead us to reject any of the AOGCMs used by Cubasch et al. (2001) in projections for the 21 st century, it does exclude substantially smaller values. Improved understanding of physical processes of climate change and refinement of climate models is essential to reducing uncertainty in climate prediction. However, reducing the uncertainty on the inputs to the method described here offers an alternative route to obtaining better constraints on climate sensitivity. For example, with $\bar{Q}^{\prime}=0.8 \mathrm{~W} \mathrm{~m}^{-2}$ and $\Delta T_{2 \times}=2.0 \mathrm{~K}$, if the ranges of uncertainty on $\bar{Q}^{\prime}$ and $\bar{F}^{\prime}$ were both $\pm 10 \%$ (the same as the present uncertainty on greenhouse-gas forcing), the 5-95\% confidence interval for $\Delta T_{2 \times}$ from this method 
would be $1.7-2.3 \mathrm{~K}$. A range as narrow as that would be a great improvement on the current state of knowledge.

Acknowledgements. We are grateful for discussions, comments and other help to Myles Allen, Tom Crowley, John Mitchell, Tom Wigley, Michael Schlesinger, John Antonov, Syd Levitus and the anonymous reviewers. Work at the Hadley Centre was supported by the UK Department of the Environment, Food and Rural Affairs under contract PECD 7/12/37 and by the Government Meteorological Research contract. Sarah Raper was supported at AWI by HGF Strategiefonds Projekt 2000/13 SEAL.

\section{REFERENCES}

Allen, M. R., N. P. Gillett, J. A. Kettleborough, G. Hegerl, R. Schnur, P. A. Stott, G. Boer, G. Covery, T. L. Delworth, G. S. Jones, J. F. B. Mitchell, and T. P. Barnett, In press: Quantifying anthropogenic influence on recent near-surface temperature change. Surveys in Geophysics.

Andronova, N. G., E. G. Rozanov, F. Yang, M. E. Schlesinger, and G. L. Stenchikov, 1999: Radiative forcing by volcanic aerosols from 1850 to 1994. J. Geophys. Res., 104, 16807-16826.

Andronova, N. G. and M. E. Schlesinger, 2001: Objective estimation of the probability density function for climate sensitivity. J. Geophys. Res., 106, 22605-22612.

Crowley, T. J., 2000: Causes of climate change over the past 1000 years. Science, 289, 270-277.

Cubasch, U., G. A. Meehl, G. J. Boer, R. J. Stouffer, M. Dix, A. Noda, C. A. Senior, S. C. B. Raper, and K. S. Yap, 2001: Projections of future climate change. Climate change 2001: The scientific basis. Contribution of Working Group I to the Third Assessment Report of the Intergovernmental Panel on Climate Change, J. T. Houghton, Y. Ding, D. J. Griggs, M. Noguer, P. van der Linden, X. Dai, K. Maskell, and C. I. Johnson, eds., Cambridge University Press, 525-582.

Folland, C. K., N. A. Rayner, S. J. Brown, T. M. Smith, S. S. P. Shen, D. E. Parker, I. Macadam, P. D. Jones, R. N. Jones, N. Nicholls, and D. M. H. Sexton, 2001: Global temperature change and its uncertainties since 1861. Geophys. Res. Let., 28, 2621-2624.

Forest, C. E., P. H. Stone, A. P. Sokolov, M. R. Allen, and M. D. Webster, 2002: Quantifying un- 
certainties in climate system properties with the use of recent climate observations. Science, $\mathbf{2 9 5}$, $113-117$.

Hoffert, M. I. and C. Covey, 1992: Deriving global climate sensitivity from paleoclimate reconstructions. Nature, 360, 573-576.

Knutti, R., T. F. Stocker, F. Joos, and G. K. Plattner, 2002: Constraints on radiative forcing and future climate change from observations and climate model ensembles. Nature, 416, 719-723.

Levitus, S., J. I. Antonov, T. P. Boyer, and C. Stephens, 2000: Warming of the world ocean. Science, 287, 2225-2229.

Levitus, S., J. I. Antonov, J. Wang, T. L. Delworth, K. W. Dixon, and A. J. Broccoli, 2001: Anthropogenic warming of the Earth's climate system. Science, 292, 267-270.

Myhre, G., E. J. Highwood, K. P. Shine, and F. Stordal, 1998: New estimates of radiative forcing due to well mixed greenhouse gases. Geophysical Research Letters, 25, 2715-2718.

Ramaswamy, V., O. Boucher, J. Haigh, D. Hauglaustaine, J. Haywood, G. Myhre, T. Nakajima, G. Y. Shi, and S. Solomon, 2001: Radiative forcing of climate change. In the same volume as Cubasch et al. (2001).

Raper, S. C. B., T. M. L. Wigley, and R. A. Warrick, 1996: Global sea-level rise: past and future. Sealevel rise and coastal subsidence, J. D. Milliman and B. U. Haq, eds., Kluwer Academic Publishers, Dordrecht.

Senior, C. A. and J. F. B. Mitchell, 2000: The time dependence of climate sensitivity. Geophys Res Lett, 27, 2685-2688.

Stott, P. A., S. F. B. Tett, G. S. Jones, M. R. Allen, J. F. B. Mitchell, and G. J. Jenkins, 2000: External control of 20th century temperature by natural and anthropogenic forcings. Science, 290, 2133-2137.

Weaver, A. J., P. B. Duffy, M. Eby, and E. C. Wiebe, 2000: Evaluation of ocean and climate models using present-day observations and forcing. Atmos. Ocean, 38, 271-301.

Wigley, T. M. L., P. D. Jones, and S. C. B. Raper, 1997: The observed global warming record: what does it tell us? Proc. Natl. Acad. Sci. USA, 94, 8314-8320. 


\section{List of Figures}

1 Effective climate sensitivity $\Delta T_{2 \times}$ as a function of radiative forcing $\bar{Q}^{\prime}$ and heat flux $\bar{F}^{\prime}$ into the ocean for the central value of surface temperature change $\overline{\Delta T}^{\prime}$. The qualitative form of this function is the same for other choices of $\overline{\Delta T}^{\prime}$ within its range of uncertainty, which is considerably less important than those in $\bar{Q}^{\prime}$ and $\bar{F}^{\prime}$. The dashed lines parallel to the axes indicate the $\pm 2 \sigma$ intervals for $\bar{Q}^{\prime}$ and $\bar{F}^{\prime}$. The oblique lines of constant $\Delta T_{2 \times}$ are straight because they apply to constant values of $\bar{Q}^{\prime}-\bar{F}^{\prime}$. In the shaded region, $\Delta T_{2 \times}$ is negative; it is infinite on the boundary between the shaded and unshaded regions, which passes through the origin. . . . . . . . . . . . . . 11

2 Probability distribution for the effective climate sensitivity $\Delta T_{2 \times}$, computed assuming $\overline{\Delta T}^{\prime}, \bar{F}^{\prime}$ and $\bar{Q}^{\prime}$ to be normally distributed. The bin width is $0.1 \mathrm{~K}$. The vertical solid line marks the lower bound of the $90 \%$ confidence interval (5-percentile), the vertical dashed line the modal value of $\Delta T_{2 \times}$, and the vertical dotted line the median. Although the distribution is shown here only up to $10 \mathrm{~K}$, the probability of larger values was accounted for in deriving the statistics and confidence interval. . . . . . . . . . . 
Table 1: Radiative forcing difference $\bar{Q}^{\prime}\left(\mathrm{W} \mathrm{m}^{-2}\right)$ between the periods 1957-1994 and 1861-1900.

$\begin{array}{lrrr} & -2 \sigma & \text { central } & +2 \sigma \\ \text { Greenhouse gases } & 1.24 & 1.38 & 1.51 \\ \text { Sulphate aerosols } & -1.61 & -1.01 & -0.41 \\ \text { Solar irradiance changes } & 0.10 & 0.30 & 0.50 \\ \text { Volcanic aerosols } & -0.49 & -0.31 & -0.12\end{array}$


Figure 1: Effective climate sensitivity $\Delta T_{2 \times}$ as a function of radiative forcing $\bar{Q}^{\prime}$ and heat flux $\bar{F}^{\prime}$ into the ocean for the central value of surface temperature change $\overline{\Delta T^{\prime}}$. The qualitative form of this function is the same for other choices of $\overline{\Delta T^{\prime}}$ within its range of uncertainty, which is considerably less important than those in $\bar{Q}^{\prime}$ and $\bar{F}^{\prime}$. The dashed lines parallel to the axes indicate the $\pm 2 \sigma$ intervals for $\bar{Q}^{\prime}$ and $\bar{F}^{\prime}$. The oblique lines of constant $\Delta T_{2 \times}$ are straight because they apply to constant values of $\bar{Q}^{\prime}-\bar{F}^{\prime}$. In the shaded region, $\Delta T_{2 \times}$ is negative; it is infinite on the boundary between the shaded and unshaded regions, which passes through the origin.

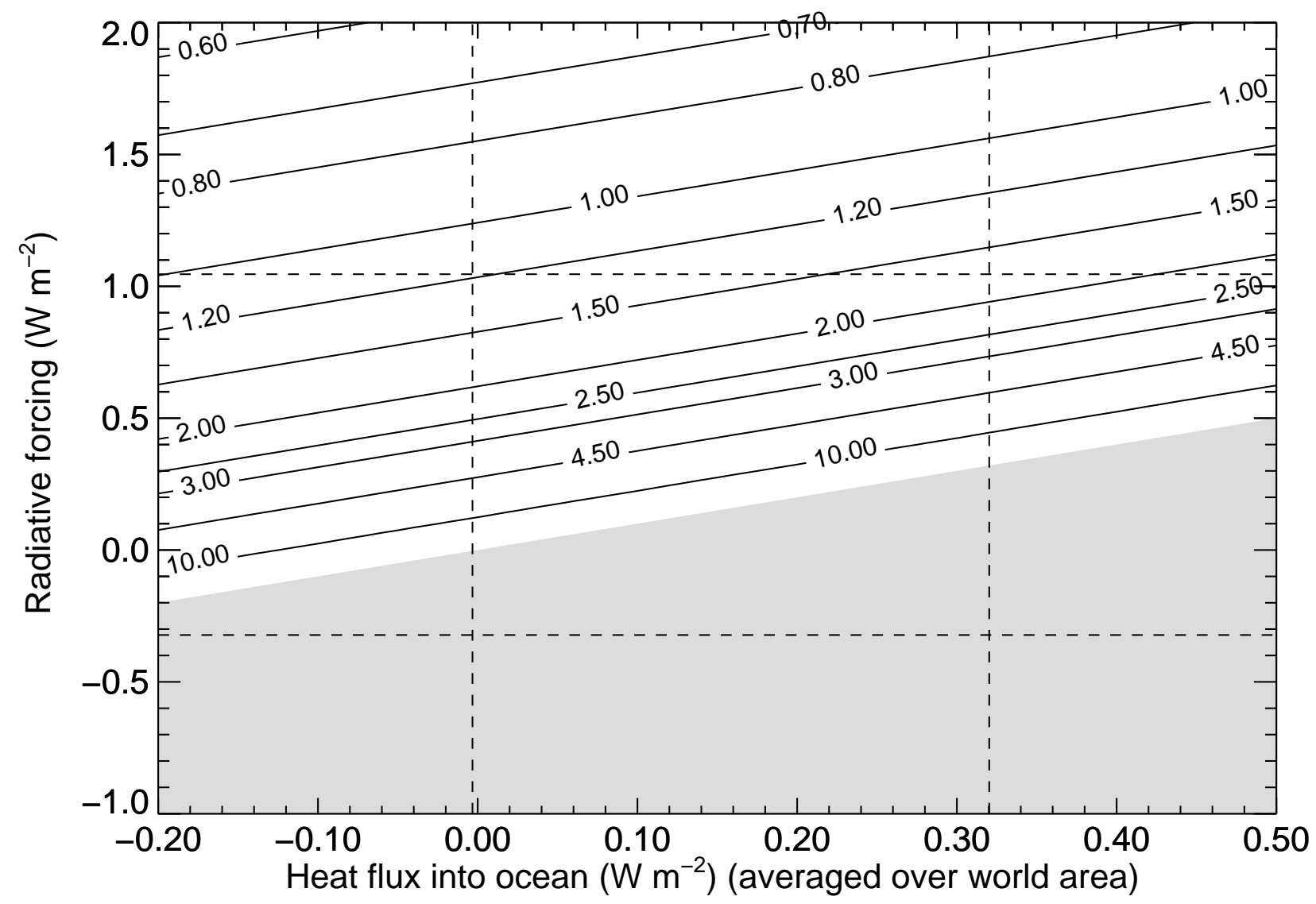


Figure 2: Probability distribution for the effective climate sensitivity $\Delta T_{2 \times}$, computed assuming $\overline{\Delta T}^{\prime}$, $\bar{F}^{\prime}$ and $\bar{Q}^{\prime}$ to be normally distributed. The bin width is $0.1 \mathrm{~K}$. The vertical solid line marks the lower bound of the $90 \%$ confidence interval (5-percentile), the vertical dashed line the modal value of $\Delta T_{2 \times}$, and the vertical dotted line the median. Although the distribution is shown here only up to $10 \mathrm{~K}$, the probability of larger values was accounted for in deriving the statistics and confidence interval.

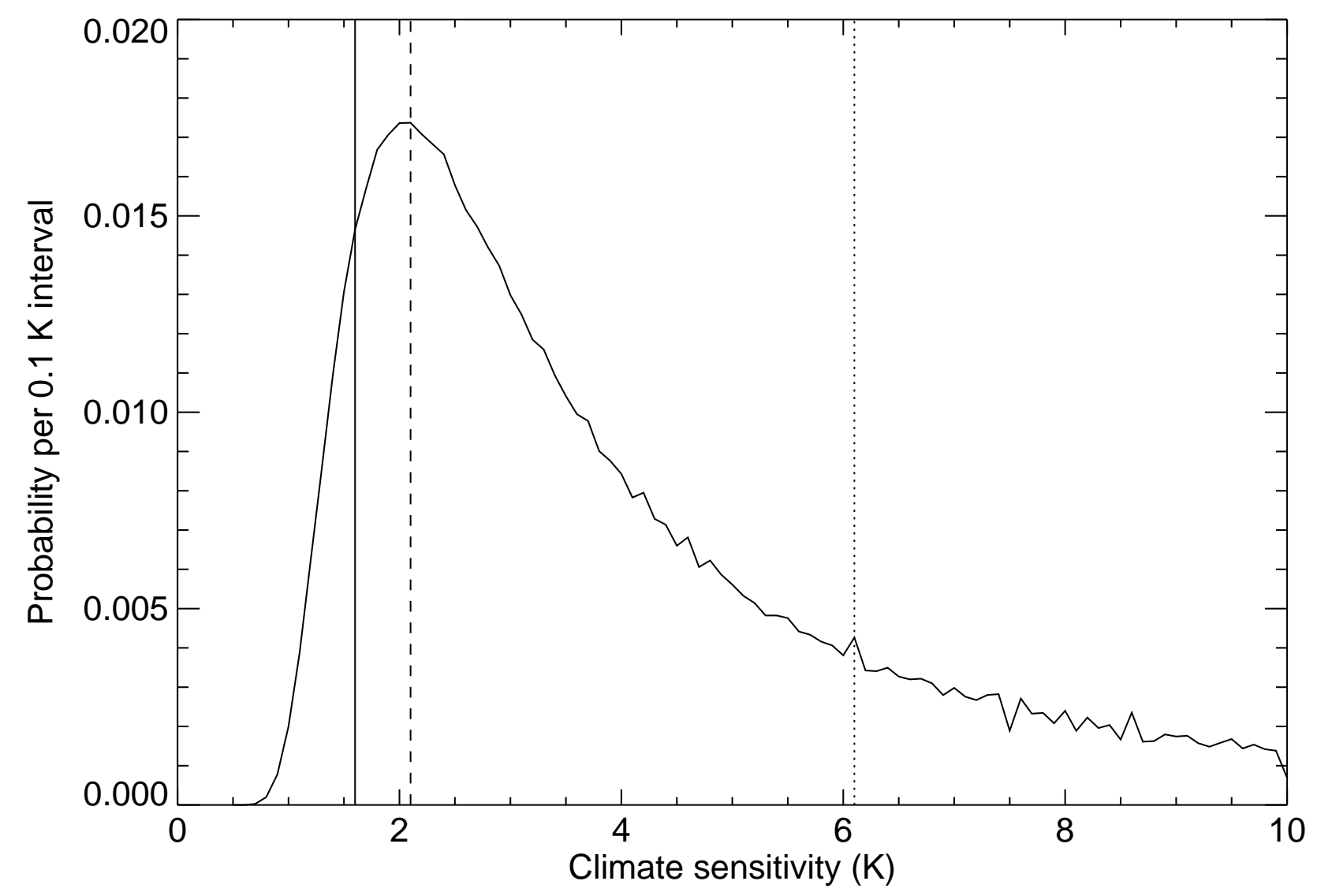

